American Journal of Applied Sciences 7 (11): 1443-1448, 2010

ISSN 1546-9239

(C) 2010 Science Publications

\title{
The Sintering Temperature Effect on the Shrinkage Behavior of Cobalt Chromium Alloy
}

\author{
${ }^{1}$ M. Ghazali Kamardan, ${ }^{2}$ N. Hidayah A. Zaidi, ${ }^{1}$ M. Noh Dalimin, ${ }^{3}$ A. Mujahid A. Zaidi, ${ }^{2}$ S. Bahrin \\ Jamaludin and ${ }^{4}$ M.Mahadi.A.Jamil \\ ${ }^{1}$ Faculty of Science, Arts and Heritage \\ University Tun Hussein Onn Malaysia, Johor Malaysia \\ ${ }^{2}$ School of Materials Engineering, University Malaysia Perlis, Perlis, Malaysia \\ ${ }^{3}$ Faculty of Engineering, National Defense University of Malaysia, Kuala Lumpur, Malaysia \\ ${ }^{4}$ Faculty of Electrical Engineering, University Tun Hussein Onn Malaysia, Johor Malaysia
}

\begin{abstract}
Problem Statement: Co-Cr based alloys which is well known for its high Young's modulus, fatigue strength, wear resistance and corrosion resistance is an important metallic biomaterial. However, till date there are only two type of $\mathrm{Co}-\mathrm{Cr}$ alloy which are the castable and wrought cobalt alloy. Powder Metallurgy route for cobalt is expected to give better result of Co-Cr alloy. The purpose of this research was mainly to study the sintering temperature effect to the shrinkage behavior of Cobalt Chromium (Co-Cr) alloy of the powder metallurgy route. Approach: $\mathrm{Co}-\mathrm{Cr}$ was produced following $\mathrm{P} / \mathrm{M}$ route under sintering temperature of $1000,1100,1200,1300$ and $1400^{\circ} \mathrm{C}$. The sintering time was fixed at $60 \mathrm{~min}$. Several tests has been conducted to determine this effect such as the rate of shrinkage measurement, the bulk density and porosity percentage measurement, compression and hardness tests and micro structural study. Result: From the study, it was found that the sintering temperature has caused the shrinkage of Co-Cr. The increasing of the sintering temperature has caused to the increasing of shrinkage of Co-Cr. This has resulted to the reduction of the pore volume and hence increased it density. In conjunction to that, the strength and the hardness of $\mathrm{Co}-\mathrm{Cr}$ was increased. Conclusion: Therefore, it is hope that it will bring new view of powder metallurgy $\mathrm{Co}-\mathrm{Cr}$ alloy as bio-material.
\end{abstract}

Key words: Powder metallurgy, sintering temperature, Powder Metallurgy (P/M), cobalt chromium, shrinkage behavior

\section{INTRODUCTION}

Nowadays, Powder Metallurgy, (P/M) has become the most diverse manufacturing approach among the various metalworking technologies. $\mathrm{P} / \mathrm{M}$ is the technology of powdered metals, especially the production and utilization of metallic powders for fabricating massive materials and shaped objects. P/M techniques were initially developed to overcome problem of the alignment of carbide in strings which occur in wrought processing (Gimenez et al., 2008). Other advantage of Powder Metallurgy (P/M) is the ability to fabricate of the components with complex geometries (Robert-Perron et al., 2005). In fact, there were also several studies on the tensile, impact and fatigue resistance of the $\mathrm{P} / \mathrm{M}$ materials which has shown good results (Abdoos et al., 2009; Sudhakar, 2000; Cristofolini et al., 2010). Simchi et al. (2006) has determined that by binding the products with different properties in various locations, or composite components using $\mathrm{P} / \mathrm{M}$ process will reduce the cost and manufacturing step plus eliminate the welding process.

$\mathrm{P} / \mathrm{M}$ is an economically efficient method since it produces with almost no raw material loss of moderate to high volume material (Sudhakar, 2000).The necessity of secondary shaping operations like machining was reduced due to this near net shape process (RobertPerron et al., 2006). The development of binding and lubrication process and the application of warm compaction lubrication have resulting a better green product. In addition, excellent holes were obtained by the optimum drilling procedure. Green machining or machining the green part before sintering process is also suggested since this will reduce tool wear (RobertPerron et al., 2005).

Corresponding Author: A. Mujahid A. Zaidi, Faculty of Engineering, National Defense University of Malaysia, Kuala Lumpur, Malaysia (Email: mujahid@upnm.edu.my) 
Shrinkage of the green part or the volume decreasing is the phenomena of sintering (Yahya et al., 2009). Shrinkage affecting product quality, cost and process efficiency since it may change the dimension and the geometry precision of the product. The higher sintering temperature will effecting to more shrinkage and hence leads to the increasing of density. This is because sintering reduces the total pore surface and pore volume of the green part (Cristofolini et al., 2010). However, Dourandish has found that the sintering temperature can be manipulated in order to obtain certain porosity grade of the composite layers (Dourandish et al., 2008).

Cobalt Chromium (Co-Cr) based alloys which has been used in this study was introduced in 1930s is well known for its high Young's modulus, fatigue strength, wear resistance and corrosion resistance (GonzalezCarasco, 2009). Due to that, cobalt has become one of the most popular metallic metal alloys in the medical application for many decades. The castable cobalt alloy, CoCrMo has been used in the casting of dentistry and artificial joint product. Whereas the wrought by hot forging cobalt alloy, CoNiCrMo due to it high mechanical strength with high fracture toughness, has been used as cyclic load-bearing implants such as hip and knee joints (Park and Lakes, 2007). However, P/M route for cobalt is expected to produce the more excellent quality of alloy compared with those procedures. This study was done to determine the sintering temperature effect on $\mathrm{P} / \mathrm{M} \mathrm{Co}-\mathrm{Cr}$ alloy upon the shrinkage behavior.

\section{MATERIALS AND METHODS}

The raw materials used in this study were cobalt powder and chromium powder. Both powders were supplied by Sigma-Aldrich. The cobalt implant alloys were prepared by mixing up the cobalt powder and chromium powder together in planetary ball mill. The composite was fabricated using uniaxial die press to form pellet shape samples. The physical properties of the powder elements are shown in Table 1.

Malvern particle size analyzer was used to analyze particle size distribution of the cobalt and chromium powders. The technique used in this study is a dry method using laser light to differentiate the size of each particle. Fig. 1 shows the histogram of particle size distribution for the powders respectively. Both powders
Table 1: Physical properties of the powder element

\begin{tabular}{llllll}
\hline & $\begin{array}{l}\text { Atomic } \\
\text { number }\end{array}$ & $\begin{array}{l}\text { Molecular } \\
\text { weight }\end{array}$ & $\begin{array}{l}\text { Density, } \\
\mathrm{g} \mathrm{mL}^{-1}\end{array}$ & $\begin{array}{l}\text { Melting } \\
\text { point }\left({ }^{\circ} \mathrm{C}\right)\end{array}$ & $\begin{array}{l}\text { Boiling } \\
\text { point }\left({ }^{\circ} \mathrm{C}\right)\end{array}$ \\
\hline Co & 24 & 58.93 & $\begin{array}{l}8.9 \mathrm{~g} \mathrm{~mL}^{-1} \\
\text { at } 25^{\circ} \mathrm{C}\end{array}$ & 1495 & 2900 \\
$\mathrm{Cr}$ & 27 & 52 & $\begin{array}{l}7.14 \mathrm{~g} \mathrm{~mL}^{-1} \\
\text { at } 25^{\circ} \mathrm{C}\end{array}$ & 1857 & 2672 \\
\hline
\end{tabular}

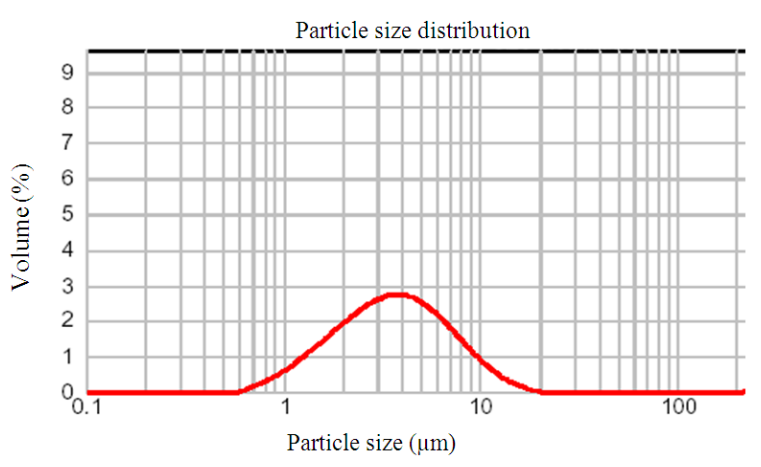

—Cobalt_stu. hidayah, Wednesday, December 21, 2005 10:44:17AM

(a)

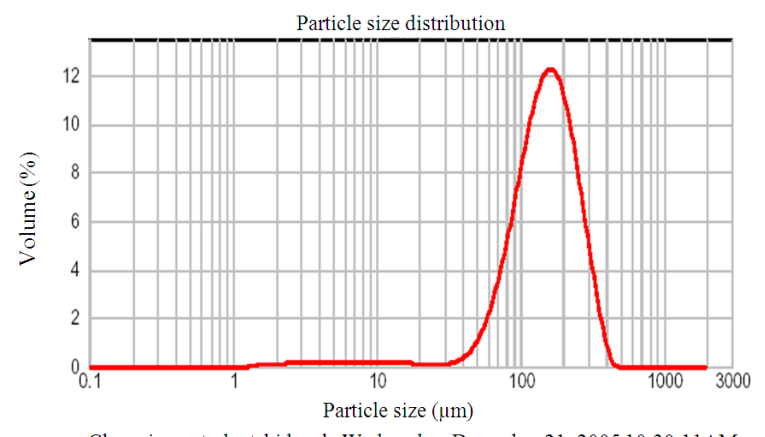

_Chromium_student. hidayah, Wednesday, December 21, 2005 10:30:11AM

(b)

Fig. 1: Particle size distribution of (a) Co powder; (b) Cr powder

show a good monomodal distribution. Along the particle size distribution, the mean particle sizes of the powders were also shown in the histogram. The mean sizes are $4 \mu \mathrm{m}$ for cobalt and $180 \mu \mathrm{m}$ for chromium powder. Powders also were examined under SEM to correlate the size of particle with the micrograph.

Figure 2 shows SEM micrographs of cobalt and chromium powders respectively. The morphology of elemental cobalt powders is ligament shape and the particle size range is between 1.25-5 $\mu \mathrm{m}$. Chromium powder that is in the irregular and polygonal shape. The size of the chromium particles is around $50-100 \mu \mathrm{m}$. The results from the SEM observation are similar with the particles size distribution determined by Malvern particle size analyzer. 


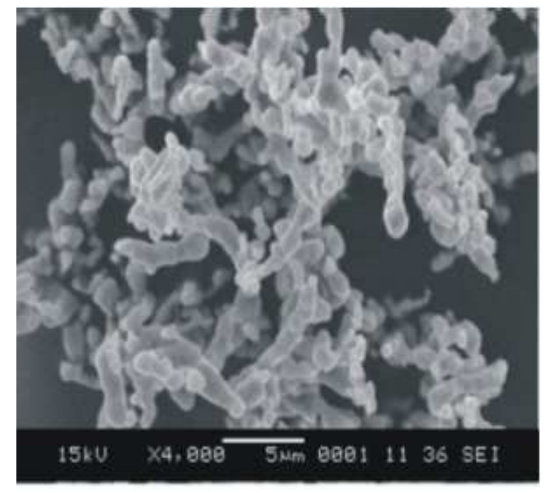

(a)

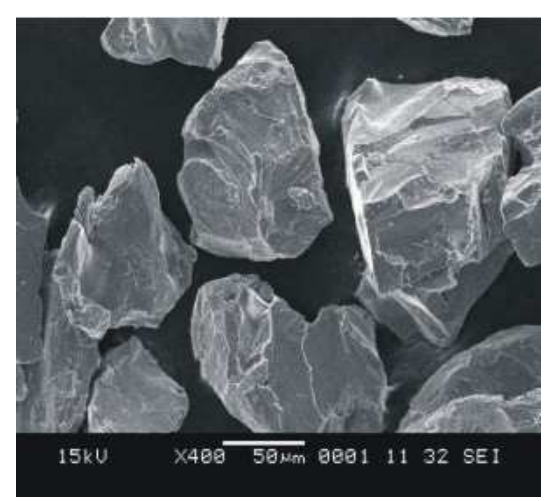

(b)

Fig. 2: SEM micrograph of the (a) Co powder; (b) $\mathrm{Cr}$ powder

Carbolite tube furnace model 2416CG was used for sintering process. Sintering process was performed in an argon atmosphere. Cobalt implant alloys were produced using cold pressing process. The die was made according to the dimension in which required for sample testing. Cobalt implant alloy pellet with $5 \mathrm{~mm}$ thickness and $19 \mathrm{~mm}$ in diameter was fabricated. Cobalt and chromium powders were mixed together in planetary ball mill (Recth, Pm100). The speed used was about $160 \mathrm{rpm}$ and was rotated for $60 \mathrm{~min}$. The powders were mixed up according to the weight ratio $\mathrm{Co}: \mathrm{Cr}$ of 7:3. The die was slightly tapped to spread the powder evenly at its bottom and a light pressure was applied (by hand) to flatten the powder layer. Sintering was performed at $1000,1100,1200,1300$ and $1400^{\circ} \mathrm{C}$ for $60 \mathrm{~min}$. Both heating and cooling ramps were $20^{\circ} \mathrm{C} \mathrm{min}^{-1}$.

Water displacement (Archimedes) method was used for the density measurement. Electronic balance (Shimadzu, type MD-300S) was the instrument used to measure the weight of the sample. Microstructure characterization of the samples was studied using optical microscope and Scanning Electron Microscope (SEM) JEOL, JSM-6420. MALVERN MASTERSIZER particle size analyzer was used to analyze particle size distribution of the cobalt and chromium powders. The technique involved was a dry method using laser light to differentiate the size of each particle. The matrix hardness was measured according to Vickers method by using Vickers micro hardness type Mitutoyo DX256 series which is completed with HM100 software for data acquisition and Vickers's micro hardness calculation. Compression test was conducted by universal testing machine (UTM, GOTECH).

\section{RESULT}

Shrinkage measurement: The diameter and the thickness of the Co-Cr green part samples were measured before and after the sintering process to determine the shrinkage. The shrinkage was determined by the diameter and the thickness reduction. The percentage of the diameter and the thickness reduction was then calculated for comparison. The calculation is done by Eq. 1 and 2:

Percent of diameter shrinkage $=\frac{d_{o}-d_{f}}{d_{o}} \times 100 \%$

Percent of thickness shrinkage $=\frac{\mathrm{h}_{\mathrm{o}}-\mathrm{h}_{\mathrm{f}}}{\mathrm{h}_{\mathrm{o}}} \times 100 \%$

Where:

$\mathrm{d}_{\mathrm{o}}=$ Diameter before sintering $(\mathrm{cm})$

$\mathrm{d}_{\mathrm{f}}=$ Diameter after sintering $(\mathrm{cm})$

$\mathrm{h}_{\mathrm{o}}=$ Height before sintering $(\mathrm{cm})$

$\mathrm{h}_{\mathrm{f}}=$ Height after sintering $(\mathrm{cm})$

Fig. 3 shows the thickness and diameter shrinkage percentage of the Co-Cr powders as a function of the sintering temperature. The graph of the shrinkage percentage for both parameters show an increasing progress from $6-11 \%$ as the sintering temperature was increased from 1000 to $1400{ }^{\circ} \mathrm{C}$.

Determination of density and porosity: The bulk density and the porosity percentage of the sintered Co$\mathrm{Cr}$ were determined based on the Archimedes' theory. The bulk density and the percentage of porosity are defined in Eq. 4 and 5:

Bulk Density $=\frac{w_{a}}{w_{c}-w_{b}} \times \rho_{\text {water }}$ 
Am. J. Applied Sci., 7 (11): 1443-1448, 2010

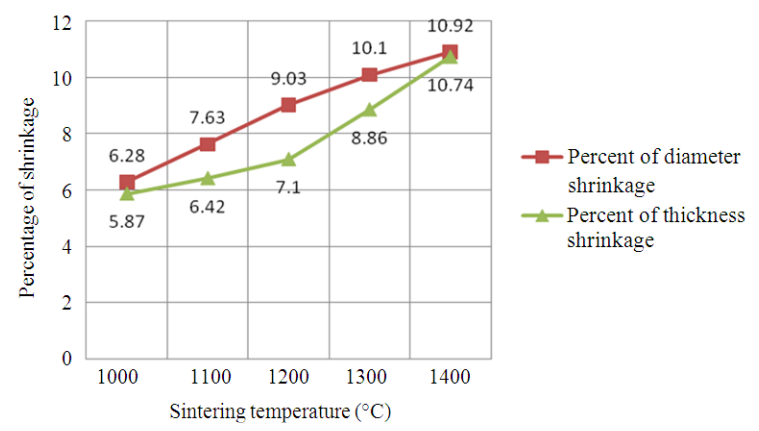

Fig. 3: Graph of the Co-Cr diameter and the thickness shrinkage percentage at different sintering temperature

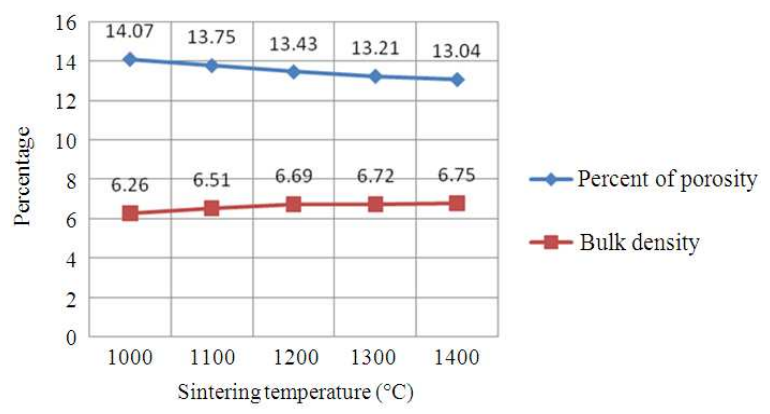

Fig. 4: Graph of Co-Cr bulk density and porosity percentage at different sintering temperature

$\%$ Porosity $=\frac{\mathrm{w}_{\mathrm{c}}-\mathrm{w}_{\mathrm{a}}}{\mathrm{w}_{\mathrm{c}}-\mathrm{w}_{\mathrm{b}}} \times 100 \%$

Where:

$\mathrm{W}_{\mathrm{a}}=$ Weight of sample in air

$\mathrm{W}_{\mathrm{b}}=$ Weight of sample in water

$\mathrm{W}_{\mathrm{c}}=$ Weight of sample in air after submerged from water

Figure 4 shows both the graph of bulk density and the graph of porosity percentage as the function of the sintering temperature. Like the graph of the shrinkage percentage, the graph of the bulk density also shown an improvement event from 6.3 to 6.8 as the sintering temperature was raised up from 1000 to $1400{ }^{\circ} \mathrm{C}$. On the other hand, the graph of the porosity percentage has shown the about $1 \%$ declining state from $14 \%$.

Compression test and hardness test: Figure 5 and 6 shows the graph of max compression loading and Vickers hardness value as the function of the sintering

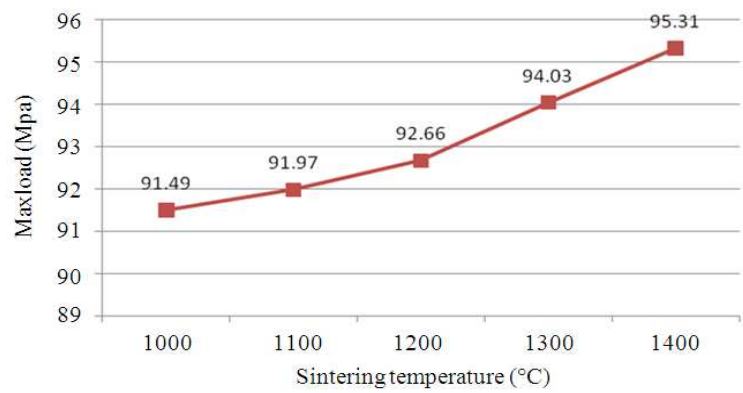

Fig. 5: Graph of $\mathrm{CoCr}$ maximum compression load (Mpa) at different sintering temperature

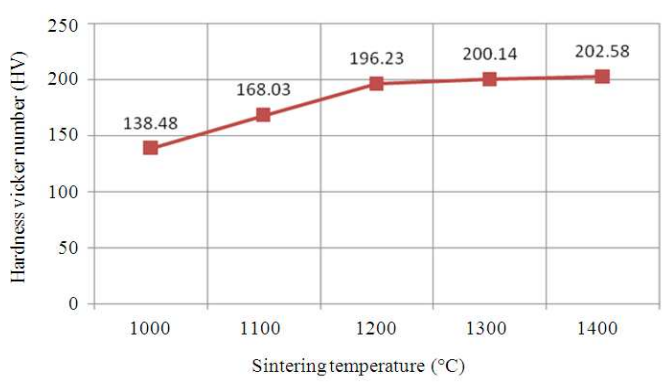

Fig. 6: Graph of $\mathrm{Co}-\mathrm{Cr}$ hardness vicker number at different sintering temperature

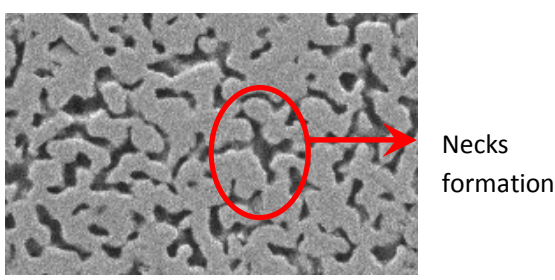

(a)
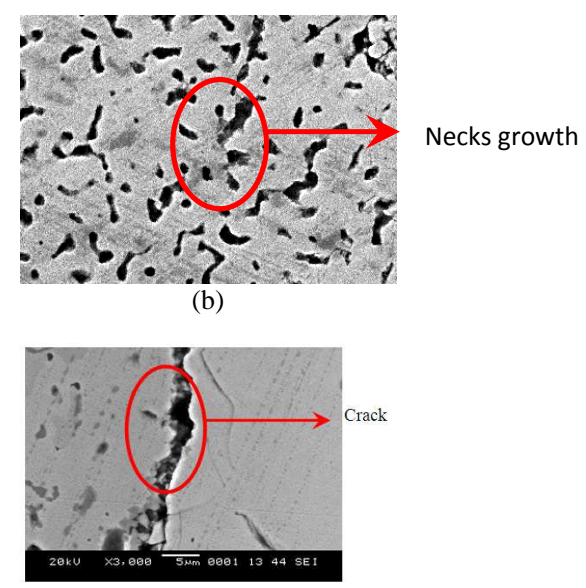

(c)

Fig. 7: SEM micrograph of the Co-Cr alloy after sintered at temperature (a) 1000; (b) 1200; (c) $1400^{\circ} \mathrm{C}$ 
temperature from 1000 to $1400{ }^{\circ} \mathrm{C}$. From Fig. 5, the max compression loading was increased from 91 to 95 Mpa. From Fig. 6, the hardness of the material was increased from 140 to 203 Vicker Number.

Micro structural study: Figure 7a-c show the SEM of the sintered $\mathrm{Co}-\mathrm{Cr}$ in argon atmosphere at sintering temperature of 1000,1200 and $1400^{\circ} \mathrm{C}$ respectively. Figure 7 a clearly showed the occurrence of neck in Co$\mathrm{Cr}$ at the sintering temperature of $1000^{\circ} \mathrm{C}$. The length of the neck was grown longer at the sintering temperature of $1200^{\circ} \mathrm{C}$ which can be observed in Fig. 7b. Finally, Fig. 7c, illustrated the disappeared of the neck and the event of the big cracks at $1400^{\circ} \mathrm{C}$.

\section{DISCUSSION}

In the shrinkage measurement experiments, both the thickness and the diameter of the green part have shown reduction after sintering process. This has shown that shrinkage has occurred after sintering. Thus, these results support the influence of the sintering temperature to the shrinkage of Co-Cr. Also, it was found that as the sintering temperature was increased from 1000 to $1400{ }^{\circ} \mathrm{C}$, the shrinkage rate of both the diameter and the thickness of $\mathrm{Co}-\mathrm{Cr}$ was increased about $5 \%$. These results showed that the increasing in the sintering temperature has affected more shrinkage of $\mathrm{Co}-\mathrm{Cr}$.

The determination of density and porosity experiments showed that the increasing in the sintering temperature has increased the density and reduced the porosity. However the change rate was less than $1 \%$ for the temperature change of $400{ }^{\circ} \mathrm{C}$. These results shown that there exist slightly increasing in shrinkage due to the increasing of the sintering temperature. On the other hand, it shown that the porosity of the material was reduced and the density was increased.

Max compression loading and Vickers hardness values were used to determine the strength and hardness of the Co-Cr after the sintering process, respectively. The max compression loading was increased about $4 \mathrm{Mpa}$ and the hardness of the material was increased about 63 Vicker Number. Both results had indicated that the strength and the hardness of $\mathrm{Co}-\mathrm{Cr}$ is also directly proportionate with sintering temperature. The enhancement of the strength and the hardness signified that the reduction of porosity and the enhancement density of Co-Cr. These results also support the influence of the sintering temperature to the shrinkage rate of the $\mathrm{Co}-\mathrm{Cr}$.

In the micro structural study, the neck formation was observed when the sintering temperature was $1000^{\circ} \mathrm{C}$ and was increased until it become a big crack at $1400^{\circ} \mathrm{C}$. The occurrences of necks, was due to the shrinkage of $\mathrm{Co}-\mathrm{Cr}$ that had forced the green part to compact. At the sintering temperature of $1400^{\circ} \mathrm{C}$, the green part become fully compact as the total pore surface and pore volume was totally removed These result have also shown that the shrinkage was increased as sintering temperature was increased.

\section{CONCLUSION}

Several tests have been done to study the shrinkage behavior of $\mathrm{Co}-\mathrm{Cr}$ due to the changing of sintering temperature. The test that being doing for this study are the rate of shrinkage measurement, the bulk density and porosity percentage measurement, compression and hardness tests and microstructural study. The whole test was done for sintering temperature of 1000, 1100, 1200,1300 and $1400^{\circ} \mathrm{C}$. The sintering time also has been fixed at $60 \mathrm{~min}$.

The diameter and the thickness measurements of $\mathrm{Co}-\mathrm{Cr}$ have shown reductions after sintering. The reduction rate was increasing. The bulk density of sintered $\mathrm{Co}-\mathrm{Cr}$ has also shown a rising rate. On the other hand, the porosity percentage of sintered $\mathrm{Co}-\mathrm{Cr}$ was declining. In contrast to that, the maximum compressing loading and the hardness measurement also was increasing.

The microstructural study has shown the formatting of neck at $1000^{\circ} \mathrm{C}$ sintering temperature. The formation of neck has been growing and turned to a big crack at $1400^{\circ} \mathrm{C}$ sintering temperature.

All these results have proven the events of the reduction of pore surface and pore volume and the increasing of the density of $\mathrm{Co}-\mathrm{Cr}$ after the sintering process. These events are the evident of the shrinkage of $\mathrm{Co}-\mathrm{Cr}$ after sintering. All these tests also have proven that the shrinkage was increasing as the sintering temperature was increased from $1000-1400^{\circ} \mathrm{C}$.

Thus, it can be concluded for the sintering of Co$\mathrm{Cr}$ in argon atmosphere for $60 \mathrm{~min}$ that:

- There will be a shrinkage after the sintering.

- The increasing of sintering temperature from 1000$1400^{\circ} \mathrm{C}$ will result to the increasing of the shrinkage.

The shrinkage has reduced the pore surface and pore volume of $\mathrm{Co}-\mathrm{Cr}$ and increased the density. Hence, it increased the strength and the hardness of $\mathrm{Co}-\mathrm{Cr}$.

Hopefully, this result will inculcate more research on the powder metallurgy $\mathrm{Co}-\mathrm{Cr}$ as bio-material. 


\section{REFERENCES}

Abdoos, H., H. Khorsand and A.R. Shahani, 2009. Fatigue behavior of diffusion bonded powder metallurgy steel with heterogeneous microstructure. Mate. Design, 30: 1026-1031. DOI: 10.1016/j.matdes.2008.06.050

Cristofolini, I., A. Rao, C. Menapace and A. Molinari, 2010. Influence of sintering temperature on the shrinkage and geometrical characteristics of steel parts produced by powder metallurgy. J. Mate. Process. Tech, 210: 1716-1725. DOI: 10.1016/j.matprotec.2010.06.002

Dourandish, M., D. Godlinski, A. Simchi and V. Firouzdor, 2008. Sintering of biocompatible P/M Co-Cr-Mo alloy (F-75) for fabrication of porositygraded composite structures. Mate. Sci. Eng., 472: 338-346. DOI: 10.1016/j.msea.2007.03.043

Gimenez, S., C. Zubizarreta, V. Trabadelo and I. Iturriza, 2008. Sintering behavior and microstructure development of T42 powder metallurgy high speed steel under different processing conditions. Mate. Sci. Eng., 480: 130-137. DOI: 10.1016/j.msea.2007.06.082

Gonzalez-Carasco, J.L., 2009. Metal as bone repair materials bone repair biomaterials, J.A. Planell, S.M. Best, D. Lacroix and A. Merolli, eds., Cambridge, ISBN: 978-1-84569-385-5, pp: 159-160.
Park, J. and R.S. Lakes, 2007. Biomaterials, 3rd Edn., Springer, ISBN: 978-0-387-37879-4, pp: 103.

Robert-Perron, E., C. Blais, S. Pelletier and Y. Thomas, 2006. Drilling of high quality features in green powder metallurgy components. Mate. Sci. Eng., 458: 195-201. DOI: 10.1016/j.msea.2006.12.050

Robert-Perron, E., C. Blais, Y. Thomas, S. Pelletier and M. Dionne, 2005. An integrated approach to the characterization of powder metallurgy components performance during green machining. Mate. Sci. Eng., $\quad 402$ : $325-334 . \quad$ DOI: 10.1016/j.msea.2005.05.019

Simchi, A., A. Rota and P. Imgrund, 2006. An investigation on the sintering behavior of $316 \mathrm{~L}$ and 17-4PH stainless steel powders for graded composites. Mate. Sci. Eng., 424: 282-289. DOI: 10.1016/j.msea.2006.03.032

Sudhakar, K.V., 2000. Fatigue behavior of a high density powder metallurgy steel. Int. J. Fatigue, 22: 729-734. PII: S0142 - 1123 (00) 00067 - 0

Yahya, N., R.A.H. Masoud, H. Daud, A.A. Aziz and H.M. Zaid, 2009. Synthesis of Al3Fe5O12 cubic structure by extremely low sintering temperature of sol gel technique. Am. J. Eng. Applied Sci., 2: 76-79. ISSN: 1941-7020 